\title{
Reduction of insulinotropic properties of GLP-1 and GIP after glucocorticoid-induced insulin resistance
}

\author{
Marie Eriksen • David H. Jensen • Siri Tribler • \\ Jens J. Holst • Sten Madsbad • Thure Krarup
}

Received: 13 October 2014 / Accepted: 26 January 2015 / Published online: 9 March 2015

(C) Springer-Verlag Berlin Heidelberg 2015

\begin{abstract}
Aims/hypothesis We evaluated the insulinotropic properties of glucagon-like peptide-1 (GLP-1) and glucose-dependent insulinotropic polypeptide (GIP) in healthy individuals at risk of developing type 2 diabetes before and after glucocorticoidinduced insulin resistance.

Methods Nineteen healthy, glucose tolerant, first-degree relatives of type 2 diabetic patients underwent OGTT and $7 \mathrm{mmol} / \mathrm{l}$ and $15 \mathrm{mmol} / \mathrm{l}$ glucose clamps with concomitant infusions of GLP-1, GIP or $\mathrm{NaCl}$ and a final infusion of arginine for determination of maximum beta cell capacity before and after treatment with dexamethasone. In addition, first-phase insulin responses were determined at $7 \mathrm{mmol} / \mathrm{l}$ and $15 \mathrm{mmol} / \mathrm{l}$ and second-phase insulin responses at $7 \mathrm{mmol} / \mathrm{l}$.

Results After dexamethasone treatment, all 19 participants had increased insulin resistance (HOMA-IR and insulin sensitivity index $[M / \mathrm{I}]$ values) and $2 \mathrm{~h}$ plasma glucose concentrations, while beta cell function indices generally increased according to the increased resistance. First-phase insulin responses induced by GLP-1 and GIP at $7 \mathrm{mmol} / \mathrm{l}$ and maximal beta cell secretory capacity did not differ before and after dexamethasone, while second-phase responses to $7 \mathrm{mmol} / 1$ and first-phase responses to $15 \mathrm{mmol} / \mathrm{l}$ glucose were reduced equally for both hormones.
\end{abstract}

M. Eriksen $(\bowtie) \cdot$ D. H. Jensen $\cdot$ S. Tribler $\cdot$ T. Krarup Department of Endocrinology, Bispebjerg University Hospital, Bispebjerg Bakke 23, DK-2400 Copenhagen, Denmark e-mail: mi.eriksen1@gmail.com

\section{J. J. Holst}

The NNF Center for Basic Metabolic Research and Department of Biomedical Sciences, The Panum Institute, University of Copenhagen, Copenhagen, Denmark

S. Madsbad

Department of Endocrinology, Hvidovre University Hospital, Hvidovre, Denmark
Conclusions/interpretation Glucocorticoid-induced insulin resistance in individuals at risk of type 2 diabetes leads to a reduced insulinotropic effect of the incretin hormones. This reduction was not associated with a decrease in the maximal beta cell secretory capacity, indicating that the reduced incretin effect in the developing dysglycaemia of the present experimental model is due to a specific early reduction of the insulinotropic effects of the incretin hormones.

Trial registration: Clinicaltrials.gov NCT02235584

Keywords Beta cell function - Glucocorticoids - Incretin · Insulin resistance

$\begin{array}{ll}\text { Abbreviations } \\ \text { FPG } & \text { Fasting plasma glucose } \\ \text { GLP-1 } & \text { Glucagon-like peptide-1 } \\ \text { GIP } & \text { Glucose-dependent insulinotropic polypeptide } \\ \text { iAUC } & \text { Incremental AUC } \\ \text { IGT } & \text { Impaired glucose tolerance } \\ \text { PG } & \text { Plasma glucose }\end{array}$

\section{Introduction}

The 'incretin effect' is mediated by two incretin hormones, glucagon-like peptide-1 (GLP-1) and glucose-dependent insulinotropic polypeptide (GIP) [1-3]. It is markedly reduced in type 2 diabetes [4,5], and is diminished in individuals with impaired glucose tolerance (IGT) [6] and obesity [7]. The reduced incretin effect found in type 2 diabetes is associated with a reduced insulinotropic effect of GLP-1 $[8,9]$ and GIP [9]. Specifically, the incretin effect of GIP is absent or severely impaired regardless of GIP dose, while an effect of GLP-1 is preserved at pharmacological levels $[8,9]$. However, few studies have examined how early in the process toward type 
2 diabetes the incretin hormones lose their insulinotropic effect. In a previous study [10], we found that the incretin effect had already diminished in individuals with an increase in insulin resistance and it deteriorated further when individuals with insulin resistance also became glucose intolerant. In that study, dexamethasone-induced insulin resistance had no effect on the secretion of the incretin hormones, which excluded impaired secretion as an explanation for the loss of incretin effect. In the current study, we therefore wanted to examine whether the insulinotropic effect of GLP-1 and GIP might be affected by glucocorticoid-induced dysglycaemia [11].

As in the previous study, insulin resistance and glucose intolerance were induced by dexamethasone treatment. We examined first-degree relatives of individuals with type 2 diabetes with normal glucose tolerance, and measured insulin secretion induced by GLP-1 and GIP during glucose clamp experiments. The insulinotropic action of the two incretin hormones is glucose-dependent [1]. We therefore examined the insulinotropic properties of the two incretin hormones at two different plasma glucose levels, $7 \mathrm{mmol} / \mathrm{l}$ and $15 \mathrm{mmol} / \mathrm{l}$, in order to capture possible changes in insulinotropic properties at physiologically as well as pathophysiologically elevated glucose levels. The infused amounts of GLP-1 and GIP were designed to copy physiologically relevant levels.

It has recently been argued that the loss of incretin effect seen in type 2 diabetes is due to a globally reduced capacity of the beta cells to secrete insulin so that the release of incretin hormones during oral stimulation cannot further increase insulin secretion, leading to an 'apparent' loss of incretin effect [12]. We therefore also investigated whether the glucocorticoid-induced reduction in the incretin effect was associated with a reduced maximal secretory response of the beta cells to arginine, a non-glucose, non-incretin beta cell stimulus.

\section{Methods}

Participants Eleven men and eight women with at least one first-degree and one second-degree relative with type 2 diabetes underwent a $75 \mathrm{~g}$ OGTT to ensure normal glucose tolerance at baseline according to WHO criteria $[13,14]$ (Table 1). All participants gave oral and written consent. The study was approved by the Scientific-Ethics Committee D of the Capital Region of Denmark (registration number H-D-2009-070). The study was conducted according to the principles of the Helsinki Declaration II (Clinicaltrials.gov registration no. NCT02235584).

Experimental design Participants were studied on four different days, with an OGTT and 3 days of glucose clamps with infusions of GLP-1, GIP and $\mathrm{NaCl}$ before and immediately after 5 days of treatment with dexamethasone; in total there
Table 1 Anthropometric data at baseline for patients

\begin{tabular}{ll}
\hline Variable & Value \\
\hline$n$ (F:M) & $8: 11$ \\
Age (years) & $27.2 \pm 1.3$ \\
BMI $\left(\mathrm{kg} / \mathrm{m}^{2}\right)$ & $25.1 \pm 0.9$ \\
FPG (mmol/l) & $5.0 \pm 0.1$ \\
PG $_{120}(\mathrm{mmol} / \mathrm{l})$ & $5.1 \pm 0.2$ \\
HOMA-IR & $0.7 \pm 0.1$ \\
\hline
\end{tabular}

Values are means \pm SEM

$\mathrm{PG}_{120}$, plasma glucose at 120 min during the $75 \mathrm{~g}$ OGTT

HOMA-IR was calculated from the fasting values from OGTT

were eight experimental days. The OGTT and the glucose clamps were performed in randomised order. Dexamethasone was given as $2 \mathrm{mg}$ twice a day for 5 days, and on study day 1,2 and 3 after the 5 days, $2 \mathrm{mg}$ dexamethasone was given in the afternoon after the tests to ensure unchanged insulin resistance. In total, every participant was treated with $26 \mathrm{mg}$ dexamethasone over 8 days. All participants were studied after an overnight $(10 \mathrm{~h})$ fast. During the OGTT, all participants ingested $75 \mathrm{~g}$ of water-free glucose dissolved in $300 \mathrm{ml}$ of water. Blood samples for glucose were collected before ingestion and after $120 \mathrm{~min}$. On the experimental days, participants took a recumbent position, an i.v. catheter was inserted into an antebrachial vein and the arm was wrapped in a heating blanket in order to arterialise the venous blood [15]. The contralateral arm was cannulated for glucose infusions ( $20 \% \mathrm{wt} / \mathrm{vol}$.). Blood samples were collected as indicated in Figs 1 and 2. At time zero (0 $\mathrm{min})$, a $50 \%$ glucose (wt/vol.) bolus was given within $1 \mathrm{~min}$ to increase plasma glucose (PG) level to $7 \mathrm{mmol} / \mathrm{l}$. The glucose bolus was calculated as: $(7 \mathrm{mmol} / \mathrm{l}$ - fasting PG) $\times 35 \mathrm{mg}$ glucose $\times$ body weight in $\mathrm{kg}$. PG level was measured at the bedside every $5 \mathrm{~min}$ and maintained at $7 \mathrm{mmol} / \mathrm{l}$ by an adjustable, continuous $20 \%$ glucose infusion. A GLP-1, GIP or $\mathrm{NaCl}$ bolus was given at time zero and followed by a continuous infusion. The GIP bolus was calculated as $120 \mathrm{pmol} / \mathrm{ml} \times 0.05 \times$ body weight in $\mathrm{kg}$, and the subsequent infusion rate was $1.5 \mathrm{pmol} /(\mathrm{kg} \times \mathrm{min})$ for $120 \mathrm{~min}$. The GLP1 bolus was calculated as: $50 \mathrm{pmol} / \mathrm{ml} \times 0.05 \times$ body weight in $\mathrm{kg}$, and the infusion rate was $0.5 \mathrm{pmol} /(\mathrm{kg} \times \min )$ for $120 \mathrm{~min}$. The infusion rates were calculated to result in postprandial plasma concentrations, as measured in our earlier study [10]. After $80 \mathrm{~min}$, the PG level was increased to $15 \mathrm{mmol} / \mathrm{l}$ (algorithm described above) and held at $15 \mathrm{mmol} / \mathrm{l}$ by means of a continuous glucose infusion, adjusted according to bedside measurements of PG level. At time $110 \mathrm{~min}$, a bolus of $5 \mathrm{~g}$ of L-arginine ( $50 \mathrm{ml}$ arginine hydrochloride, $100 \mathrm{~g} / \mathrm{l})$ was infused over $2 \mathrm{~min}$, and the experiment was terminated at time $130 \mathrm{~min}$. 
Fig. 1 Glucose, insulin and glucagon levels in plasma before and after treatment with dexamethasone during the three clamps, with infusions of GLP-1 $(\mathbf{a}, \mathbf{d}, \mathbf{g})$, GIP $(\mathbf{b}, \mathbf{e}, \mathbf{h})$ or $\mathrm{NaCl}$ (c, f, i). Black circles, before dexamethasone; white circles, after dexamethasone
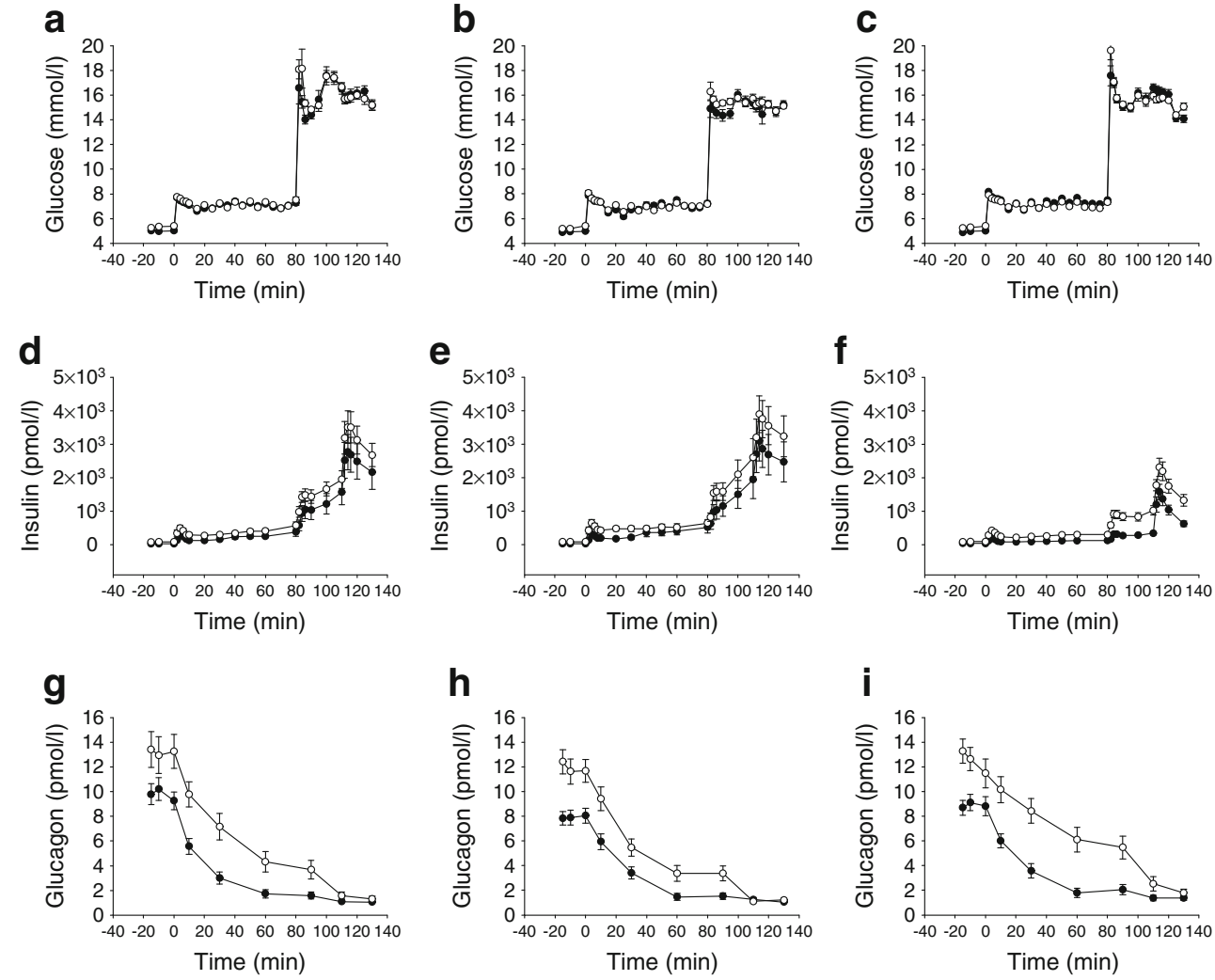

Blood samples PG level was measured at the bedside using plasma from blood collected in fluoride-containing tubes that were immediately centrifuged for $1 \mathrm{~min}$ at 7,400 $\mathrm{g}$ at room temperature. Blood for the measurement of GLP-1, GIP and glucagon levels was collected in chilled tubes containing EDTA that were immediately placed on ice and subsequently centrifuged at $4^{\circ} \mathrm{C}$ for $15 \mathrm{~min}$ at $1,200 \mathrm{~g}$. Blood for the measurement of insulin and C-peptide levels was collected in empty vials and set to coagulate before being centrifuged for $15 \mathrm{~min}$ at $1,200 \mathrm{~g}$. Plasma was stored at $-20^{\circ} \mathrm{C}$, except plasma for the measurement of insulin and C-peptide levels, which was stored at $-80^{\circ} \mathrm{C}$.

Analyses PG concentrations were measured by the glucose oxidase method, using a glucose analyser (2300 Stat Plus analyzer; YSI, Yellow Springs, OH, USA). Plasma samples were assayed for total GLP-1 as previously described [16] using a radioimmunoassay (antiserum no. 89390) specific for the C-terminal of the GLP-1 molecule that reacts equally with intact GLP-1 and the primary (N-terminally truncated) metabolite. Total GIP was measured using the C-terminally directed antiserum \#867 [17, 18], which reacts fully with intact GIP and the N-terminally truncated metabolite. The glucagon assay is directed against the C-terminus (antibody code no. 4305) and measures glucagon of mainly pancreatic origin [19-21]. Plasma insulin and Cpeptide levels were measured by the Autodelphia automatic fluoroimmunoassay (Wallac, Turku, Finland) [22].
Calculations and statistical analysis All results are expressed as means \pm SEM. AUCs were calculated using the trapezoidal rule and are presented as incremental values (baseline values subtracted). Glucose infusions were calculated as grams of glucose infused from 0 to 110 min during clamps before infusion of arginine. First-phase insulin response was calculated as incremental AUC (iAUC) during the first 10 min after the glucose bolus at PG levels of $7 \mathrm{mmol} / \mathrm{l}$ and $15 \mathrm{mmol} / \mathrm{l}$. The second-phase insulin response was calculated as iAUC from 10 to $80 \mathrm{~min}$ when clamped at $7 \mathrm{mmol} / \mathrm{l}$. Maximal insulin secretory capacity was calculated as iAUC from 110 to $130 \mathrm{~min}$ when glucose was clamped at $15 \mathrm{mmol} / \mathrm{l}$ and arginine was infused. Insulin resistance was estimated by the HOMA index [23], which was calculated using fasting values of glucose and insulin during each of the clamp days. We also calculated the insulin sensitivity index ( $M / \mathrm{I}$ ratio), relating the amount of glucose infused with insulin secretion levels during the last 20 min before arginine of the $\mathrm{NaCl}$ clamp to estimate insulin resistance. To estimate insulin extraction/clearance before and after dexamethasone we calculated the ratio of the total area under the plasma insulin curve to the total area under the plasma C-peptide curve for both the basal and the poststimulatory period during the clamps. To estimate the specific potentiating effect of the incretin hormones on insulin and C-peptide during the clamp experiments, these were compared with the effect of glucose alone as measured during the $\mathrm{NaCl}$ clamp, by dividing iAUCs during the hormone 
Fig. 2 Beta cell secretory responses. The left column shows iAUC beta cell secretory responses during the GLP-1, GIP and $\mathrm{NaCl}$ clamps. The right column shows the potentiating effect of GIP or GLP-1 relative to the $\mathrm{NaCl}$ clamp (calculated as GLP-1 or GIP results divided by $\mathrm{NaCl}$ results). iAUCs were calculated as $(\mathbf{a}, \mathbf{b})$ first phase at $7 \mathrm{mmol} / \mathrm{l}(0-10 \mathrm{~min}),(\mathbf{c}, \mathbf{d})$ second phase (10-80 $\mathrm{min}),(\mathbf{e}, \mathbf{f})$ first phase at $15 \mathrm{mmol} / 1(80$ $90 \mathrm{~min}$ ), (g, h) maximal insulin response per minute (110$130 \mathrm{~min}$ ), and $(\mathbf{i}, \mathbf{j})$ total response (0-130 min). Black columns: before dexamethasone; grey columns: after dexamethasone. ${ }^{*} p<0.05$ b
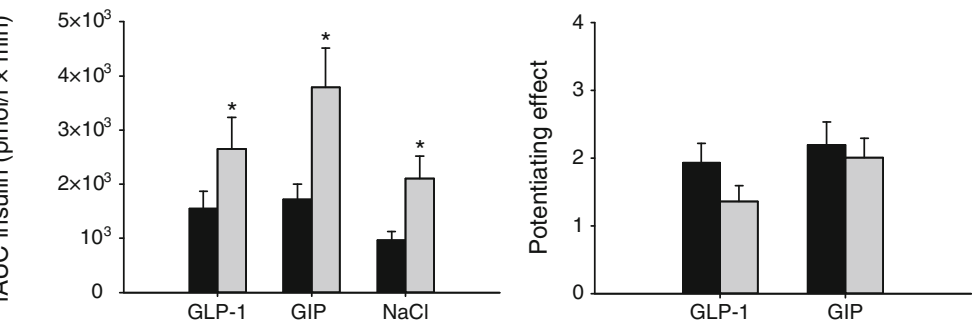

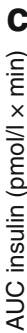
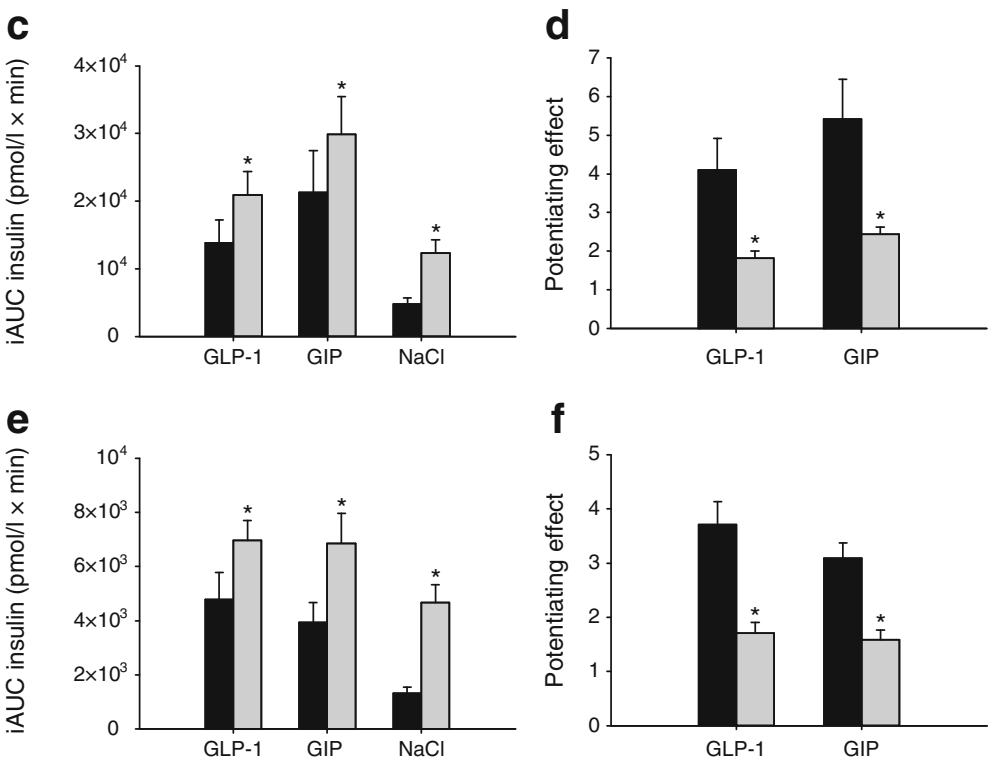

f

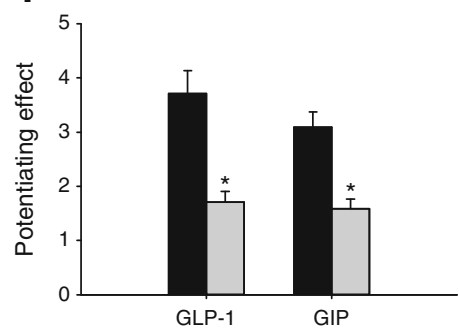

h
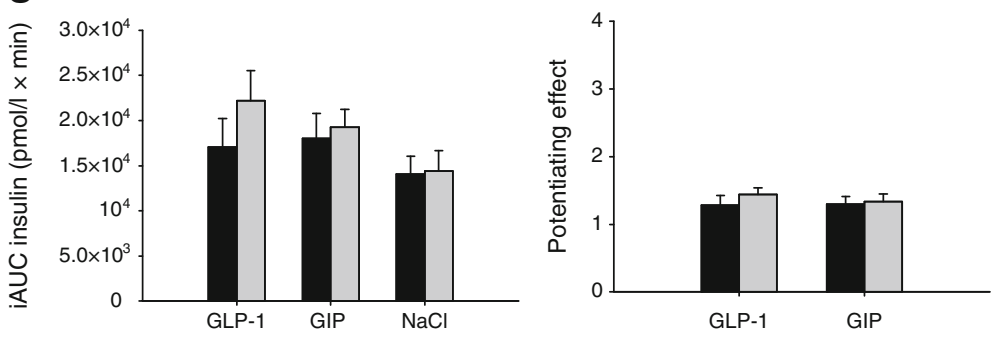

i

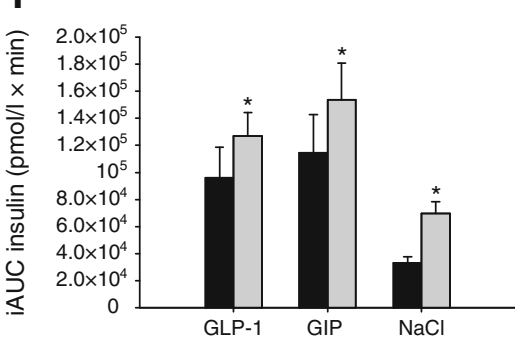

clamp experiments with the iAUCs obtained during the $\mathrm{NaCl}$ clamp experiments. When the three clamps were compared, Friedman's two-way analysis of variance was used, and when significant difference was found, the Wilcoxon's test was used for evaluation of within group differences. A $p$ value $<0.05$ was considered statistically significant.

\section{Results}

Glucose Fasting PG (FPG) concentrations were similar on all the three clamp days both before and after dexamethasone, but dexamethasone increased FPG from $5.0 \pm 0.01 \mathrm{mmol} / 1$ to $5.2 \pm$ $0.04 \mathrm{mmol} / \mathrm{l}(p<0.05)$. After dexamethasone, an increase in 
plasma glucose at 120 min during the OGTT was seen in all individuals (from $5.1 \pm 0.2 \mathrm{mmol} / 1$ before to $6.3 \pm 0.3 \mathrm{mmol} / 1$ after dexamethasone, $p<0.05)$. Furthermore, three individuals developed IGT (120 min plasma glucose $>7.8 \mathrm{mmol} / \mathrm{l})$. The amount of glucose infused during the clamp before and after dexamethasone was $95 \pm 5 \mathrm{~g}$ and $65 \pm 6 \mathrm{~g}$ for GLP-1 $(p<0.05)$, $99 \pm 9 \mathrm{~g}$ and $65 \pm 5 \mathrm{~g}$ for GIP $(p<0.05)$, and $55 \pm 5 \mathrm{~g}$ and $46 \pm$ $4 \mathrm{~g}$ for $\mathrm{NaCl}(p<0.05)$, respectively.

HOMA index HOMA-IR increased in all participants after dexamethasone, from $0.7 \pm 0.1$ before to $1.7 \pm 0.2$ after $(p<0.05)$ with no differences between the three clamp days. The $M / \mathrm{I}$ ratio during the last $20 \mathrm{~min}$ before arginine of the $\mathrm{NaCl}$ hyperglycaemic clamp decreased from $0.04 \pm 0.008$ before to $0.01 \pm 0.002$ (mmol glucose) $\mathrm{min}^{-1} /\left(\mathrm{pmol}\right.$ insulin) $1^{-1}$ $(p<0.05)$ after dexamethasone.

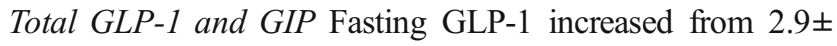
$0.4 \mathrm{pmol} / 1$ to $4.9 \pm 0.6 \mathrm{pmol} / 1$ after dexamethasone $(p<0.05)$. Fasting GIP was unchanged $(7.8 \pm 1.1 \mathrm{pmol} / 1$ to $9.4 \pm 1.6 \mathrm{pmol} / \mathrm{l} ; p>0.05)$. The mean steady state concentrations during the GLP-1 and GIP clamp were $27 \pm 5 \mathrm{pmol} / 1$ and $147 \pm 27 \mathrm{pmol} / 1$ before compared with $31 \pm 5 \mathrm{pmol} / 1$ and $155 \pm 29 \mathrm{pmol} / \mathrm{l}$ after dexamethasone $(p>0.05)$, respectively. In addition, GLP-1 iAUCs during the GLP-1 clamp were similar before $(3,607 \pm 147 \mathrm{pmol} / 1 \times \mathrm{min})$, and after $(3,828 \pm$ $236 \mathrm{pmol} / 1 \times \min )$ dexamethasone $(p>0.05)$. Total iAUCs of GIP during the GIP clamp were also similar before and after dexamethasone $(20,911 \pm 1,035 \mathrm{pmol} / 1 \times \min$ vs $22,002 \pm$ $890 \mathrm{pmol} / 1 \times \min , p>0.05$ ). During the $\mathrm{NaCl}$ clamp, secretion of incretin hormones was negligible.

Fasting insulin Fasting insulin values were similar on the three experimental days before and after dexamethasone. After treatment, fasting values increased significantly for
GLP-1, GIP and $\mathrm{NaCl}$ (GLP-1 $33 \pm 6 \mathrm{pmol} / 1$ to $79 \pm 13 \mathrm{pmol} /$ 1, GIP $36 \pm 6 \mathrm{pmol} / 1$ to $89 \pm 12 \mathrm{pmol} / 1$, and $\mathrm{NaCl} 37 \pm 7 \mathrm{pmol} / 1$ to $86 \pm 14 \mathrm{pmol} / \mathrm{l} ; p<0.05$ for all; Fig. 1$)$.

Beta cell secretory responses The insulin responses (iAUCs, $\mathrm{pmol} / \mathrm{l} \times \mathrm{min}$ ) are shown in Table 2 .

First-phase insulin responses at $7 \mathrm{mmol} / 1(0-10 \mathrm{~min})$ increased significantly for all clamps after dexamethasone treatment (GLP-1 69\%, GIP 124\% and $\mathrm{NaCl} 119 \%$; $p<0.05$ for all; Fig. 2, Table 2). Second-phase responses (10-80 $\mathrm{min})$ increased significantly for all clamps after dexamethasone (GLP-1 50\%, GIP 43\%, NaCl 150\%; $p<0.05$ for all; Fig. 2, Table 2). First-phase insulin response at $15 \mathrm{mmol} / \mathrm{l}(80$ $90 \mathrm{~min}$ ) increased significantly for all clamps after dexamethasone (GLP-1 40\%, GIP 77\%, $\mathrm{NaCl} 262 \% ; p<0.05$ for all; Fig. 2, Table 2). After arginine infusion, a further increase in insulin secretion was induced during all clamps, but the iAUC maximum insulin responses (110-130 min) did not differ during any of the clamps before compared with after dexamethasone (Fig. 2). Before dexamethasone, maximal insulin response during GIP infusion increased by $29 \%$ compared with that during $\mathrm{NaCl}$ infusion $(p<0.05)$. During GLP-1 infusion the increase was not statistically significant. After dexamethasone, the maximal insulin response during GLP-1 and GIP infusion increased by $57 \%(p<0.05)$ and $36 \%(p<0.05)$, respectively, compared with that during $\mathrm{NaCl}$ infusion. The total iAUC during the whole clamp increased significantly during GLP-1 infusion by $32 \%$, during GIP infusion by $35 \%$ and during $\mathrm{NaCl}$ infusion by $141 \%$ ( $p<0.05$ for all; Fig. 2, Table 2).

Potentiating effect of GLP-1 and GIP The potentiating effect on insulin secretion relative to $\mathrm{NaCl}$ (calculated as GLP-1 or GIP results divided by $\mathrm{NaCl}$ results) are shown in Table 3 . The first-phase insulin responses at $7 \mathrm{mmol} / 1(0-10 \mathrm{~min})$ relative to

Table 2 iAUC beta cell secretory responses (pmol/1× min) during the GLP-1, GIP and $\mathrm{NaCl}$ clamps

\begin{tabular}{|c|c|c|c|c|c|c|}
\hline \multirow[t]{2}{*}{ Insulin iAUC (pmol/1× min) } & \multicolumn{3}{|c|}{ Before dexamethasone } & \multicolumn{3}{|c|}{ After dexamethasone } \\
\hline & GLP-1 clamp & GIP clamp & $\mathrm{NaCl}$ clamp & GLP-1 clamp & GIP clamp & $\mathrm{NaCl}$ clamp \\
\hline First phase $(7 \mathrm{mmol} / \mathrm{l})$ & $1,555 \pm 312^{\dagger}$ & $1,720 \pm 278^{\dagger}$ & $964 \pm 167$ & $2,653 \pm 583^{*}, \dagger$ & $3,789 \pm 722^{*, \dagger}$ & $2,100 \pm 414 *$ \\
\hline Second phase & $13,841 \pm 3,417^{\dagger}$ & $21,302 \pm 6,173^{\dagger}$ & $4,810 \pm 865$ & $20,948 \pm 3,428^{*, \dagger}$ & $29,857 \pm 5,541^{*, \dagger}$ & $12,307 \pm 2,006^{*}$ \\
\hline First phase $(15 \mathrm{mmol} / \mathrm{l})$ & $4,790 \pm 988$ & $3,931 \pm 743$ & $1,323 \pm 216$ & $6,970 \pm 736^{*}$ & $6,855 \pm 1,106^{*}$ & $4,678 \pm 654^{*}$ \\
\hline Maximal insulin response & $17,048 \pm 3,192$ & $18,045 \pm 759^{*}$ & $14,071 \pm 259$ & $22,193 \pm 33^{\ddagger}$ & $19,273 \pm 1,984^{*}$ & $14,421 \pm 259$ \\
\hline Total insulin & $96,134 \pm 22,415$ & $114,425 \pm 28,400$ & $33,016 \pm 4,556$ & $126,948 \pm 17,260 *$ & $153,681 \pm 26,994 *$ & $69,803 \pm 8,550 *$ \\
\hline
\end{tabular}

Values are means \pm SEM

iAUCs were calculated as first phase at $7 \mathrm{mmol} / 1(0-10 \mathrm{~min})$, second phase $(10-80 \mathrm{~min})$, first phase at $15 \mathrm{mmol} / 1(80-90 \mathrm{~min})$, maximal insulin response after arginine stimulation (110-130 $\mathrm{min})$ and total insulin (0-130 min)

*Significant difference before and after treatment with dexamethasone

${ }^{\dagger}$ Significant difference between GLP-1 and GIP

${ }^{\star}$ For maximal insulin response: a significant difference between $\mathrm{NaCl}$ and GLP-1 or GIP 
$\mathrm{NaCl}$ did not differ before or after dexamethasone treatment during either GLP-1 or GIP clamps ( $p>0.05$; Fig. 2, Table 3 ). The potentiating effect relative to $\mathrm{NaCl}$ for second-phase insulin responses (10-80 $\mathrm{min}$ ), first-phase insulin response at $15 \mathrm{mmol} / 1$ (80-90 $\mathrm{min}$ ), and total iAUC during the clamp decreased for both GLP-1 and GIP after dexamethasone treatment $(p<0.05$; Fig 2, Table 3$)$. The potentiating effect of GLP-1 and GIP on the arginine-induced insulin response (maximal insulin response) was similar before and after dexamethasone treatment and did not differ between GLP-1 and GIP (Fig. 2, Table 3).

C-peptide values and insulin extraction/clearance C-peptide results confirmed the results using the insulin data (data not shown). During the $\mathrm{NaCl}$ clamp the basal insulin extraction/ clearance was $22 \pm 1$ before and $26 \pm 1$ after dexamethasone $(p<0.05)$. During the clamps, the ratios before and after dexamethasone were $60 \pm 5$ and $67 \pm 4$ (GLP-1, $p<0.05), 64 \pm 6$ and $71 \pm 5$ (GIP, $p<0.05$ ), and $42 \pm 3$ and $55 \pm 4(\mathrm{NaCl}, p<0.05)$, respectively, indicating a reduced extraction/clearance of insulin after dexamethasone.

Glucagon Fasting glucagon values were similar on the three experimental days before dexamethasone. Fasting plasma glucagon increased significantly after dexamethasone on all three experimental days, but the degree of suppression of glucagon did not differ at $120 \mathrm{~min}$ before and after dexamethasone or between the GLP-1 and GIP clamps (Fig. 1).

\section{Discussion}

In the present study, we induced a dysglycaemic state by treating healthy first-degree relatives of type 2 diabetic patients with dexamethasone in order to determine how this might influence the actions of the incretin hormones, with a view to understanding how the impaired incretin effect in individuals with insulin resistance develops. The key findings are that the insulinotropic effects of the two incretin hormones GLP-1 and GIP did not change when measured as first-phase insulin responses to a glucose clamp at $7 \mathrm{mmol} / \mathrm{l}$ and as maximal insulin responses to arginine at $15 \mathrm{mmol} / \mathrm{l}$. By contrast, the potentiating effects of both GLP-1 and GIP on secondphase insulin responses at $7 \mathrm{mmol} / \mathrm{l}$ and first-phase insulin responses at $15 \mathrm{mmol} / 1$ were significantly impaired after dexamethasone. Nevertheless, all insulin responses were increased after dexamethasone, suggesting that the beta cells adapted to the increase in insulin resistance, but were unable to fully compensate for this, since glucose tolerance decreased in all individuals and the amount of glucose infused was decreased during all three clamps after dexamethasone.

We previously demonstrated that the incretin effect was reduced when insulin resistance was increased with dexamethasone in healthy first-degree relatives of type 2 diabetes patients, even while normal glucose tolerance was maintained [10]. When the participants developed glucose intolerance in addition to insulin resistance, a further significant decline in the incretin effect was observed. In that study, neither GLP-1 nor GIP responses changed during the OGTT after dexamethasone, and therefore could not explain the loss of incretin effect. Another study actually showed an increase in GIP secretion after glucocorticoid treatment [24].

Therefore, in the present study, we investigated in detail the effects on different measures of beta cell function of both GLP-1 and GIP in concentrations similar to those observed after oral glucose and a mixed meal in a previous study measured with the same assays [10]. We used the same protocol as in the previous study to induce insulin resistance and dysglycaemia. In the current study, dexamethasone resulted in more than a doubling in insulin resistance, but only three of the participants developed IGT. Our participants may

Table 3 The potentiating effect of GIP or GLP-1 relative to the NaCl clamp (calculated as GLP-1 or GIP results divided by NaCl results)

\begin{tabular}{|c|c|c|c|c|}
\hline \multirow[t]{2}{*}{ Insulin iAUC } & \multicolumn{2}{|c|}{ Before dexamethasone } & \multicolumn{2}{|l|}{ After dexamethasone } \\
\hline & GLP-1/NaCl clamp & $\mathrm{GIP} / \mathrm{NaCl}$ clamp & GLP-1/NaCl clamp & $\mathrm{GIP} / \mathrm{NaCl}$ clamp \\
\hline First phase $(7 \mathrm{mmol} / \mathrm{l})$ & $1.9 \pm 0.28$ & $2.2 \pm 0.33$ & $1.4 \pm 0.2^{\dagger}$ & $2.0 \pm 0.28^{\dagger}$ \\
\hline Second phase & $4.1 \pm 0.81^{\dagger}$ & $5.4 \pm 1.0^{\dagger}$ & $1.8 \pm 0.19^{*, \dagger}$ & $2.4 \pm 0.19^{*, \dagger}$ \\
\hline First phase $(15 \mathrm{mmol} / \mathrm{l})$ & $3.7 \pm 0.42$ & $3.1 \pm 0.28$ & $1.7 \pm 0.2^{*}$ & $1.6 \pm 0.17^{*}$ \\
\hline Maximal insulin response & $1.3 \pm 0.14$ & $1.3 \pm 0.11$ & $1.4 \pm 0.10$ & $1.3 \pm 0.14$ \\
\hline Total insulin & $2.8 \pm 0.23^{\dagger}$ & $3.1 \pm 0.28^{\dagger}$ & $1.8 \pm 0.12 *$ & $2.1 \pm 0.15^{*}$ \\
\hline
\end{tabular}

Values are means \pm SEM

iAUCs were calculated as first phase at $7 \mathrm{mmol} / \mathrm{l}(0-10 \mathrm{~min})$, second- phase (10-80 min), first phase at $15 \mathrm{mmol} / 1$ ( $80-90 \mathrm{~min})$, max response per minute after arginine stimulation (110-130 $\mathrm{min})$ and total insulin (0-130 $\mathrm{min})$

*Significant difference before and after treatment with dexamethasone

${ }^{\dagger}$ Significant difference between GLP-1 and GIP 
therefore be viewed as being in a very early dysglycaemic state, which suggests that our results may be representative of early pathogenetic traits in the path toward type 2 diabetes.

Notably, the effects of glucocorticoids resemble the insulin resistance seen in type 2 diabetes: reduced insulin-mediated peripheral glucose disposal $[25,26]$, reduced oxidative and non-oxidative pathways of glucose disposal [25], reduced muscle glycogen synthase activity [27] and hepatic insulin resistance [26]. In the present study, however, dexamethasone did not impair beta cell function as such because the maximal response of the beta cells did not change after treatment.

Dexamethasone treatment with induction of insulin resistance significantly increased all beta cell indices during the glucose alone and glucose plus GLP-1 and GIP clamps. To estimate the specific potentiating effects of the incretin hormones on glucose-induced insulin secretion we, therefore, related the iAUCs during the GLP-1 and GIP clamps to the iAUC during the $\mathrm{NaCl}$ clamp. The potentiating effect of the two hormones on the first-phase insulin response at a glucose level of $7 \mathrm{mmol} / \mathrm{l}$ was unchanged before and after dexamethasone treatment. This finding is in contrast to the effect on the second-phase insulin response, in which the potentiating effect decreased for both hormones after dexamethasone. At $15 \mathrm{mmol} / \mathrm{l}$ glucose, the potentiating effect of both hormones on first-phase insulin response also decreased significantly, while the effect on insulin secretion induced by the nonglucose beta cell secretagogue arginine remained unchanged.

Insulin secretion is a complex process. The first-phase insulin response represents the release of insulin from a small pool of readily releasable granules docked on, or in close proximity to, the plasma membrane, while the subsequent second phase of insulin release is primarily derived from stored secretory granules and, with prolonged exposure to glucose, from de novo insulin synthesis [28].

The present results indicate that the earliest identifiable incretin deficiency of GLP-1 and GIP involves the insulin secretory machinery in the more distal steps, which involve mobilisation of stored secretory granules and de novo insulin synthesis. This incretin deficiency underlies the impaired second-phase insulin response in the current study. The potentiating effect of GLP-1 and GIP was also impaired in the firstphase insulin response at a glucose level of $15 \mathrm{mmol} / \mathrm{l}$. However, the first-phase insulin response at $15 \mathrm{mmol} / \mathrm{l}$ may not represent a 'real' first-phase insulin response, since it was performed immediately after the $7 \mathrm{mmol} / \mathrm{l}$ clamp without any wash-out period and therefore partly reflects the preceding second phase. Stimulation with the non-glucose beta cell stimulus arginine illustrates that a first-phase insulin response could still be produced if another intracellular beta cell pathway than that used by GLP-1 and GIP is stimulated. Importantly, the arginine response was unaffected by dexamethasone, indicating that the diminished incretin action of the two hormones is not related to a global dysfunction of the beta cells [12]. Rather, our results indicate that the impaired insulinotropic effects of GLP-1 and GIP represent a very early, specific beta cell defect, which can explain the impaired incretin effect in, for instance, obese individuals with insulin resistance [29]. A reduced effect of GIP in first-degree relatives of patient with type 2 diabetes and in women with a history of gestational diabetes has been found in previous studies [30, 31].

The molecular explanation for the reduced incretin effects as demonstrated in the present study is unknown, but this very early beta cell defect has been found in parallel with an increased proinsulin/C-peptide ratio, reflecting increased demand for insulin [10,32]. This is in accordance with insulin resistance induced by dexamethasone in the present study. The insulin resistance, therefore, seems indirectly to be part of the explanation for the reduced incretin effect in the present study $[6,7,10]$.

Arginine stimulation during a $15 \mathrm{mmol} / \mathrm{l}$ glucose clamp is generally considered a reliable measure of beta cell secretory capacity. Interestingly, however, when adding GLP-1 or GIP to the clamp, the insulin response increased significantly, indicating that estimation of true beta cell secretory capacity requires a combination of multiple stimuli [33].

In type 2 diabetes patients, it has been shown that firstphase responses to GIP and GLP-1 are both diminished, but still present, whereas the late-phase response to GIP is almost completely lost, even at supraphysiological levels [34]. By contrast, GLP-1 at supraphysiological levels is still able to generate a second-phase response [9]. Interestingly, in our participants with dysglycaemia, GIP was able to generate a similar insulin response as GLP-1 in both the first and second phase. This finding shows that the severe beta cell secondphase insensitivity to GIP observed in type 2 diabetes is not an early trait in the pathophysiology of the disease.

The relative increase in insulin responses after dexamethasone during the $\mathrm{NaCl}$ glucose clamp was similar to or greater than that during the glucose plus GLP-1 and GIP clamps. This result is surprising since beta cell insensitivity to glucose is considered a very early beta cell defect in the development of type 2 diabetes. However, this finding also means that the reduced effect of the incretin hormones in the present study cannot be explained by an insufficient general ability of the beta cell to secrete insulin, but must be due to a more specific defect in the insulinotropic actions of the two incretin hormones, GLP-1 and GIP. Taken together, the present study illustrates that dexamethasone-induced insulin resistance is also a model of beta cell failure (and reduction of GLP-1/ GIP insulinotropic effects) secondary to the induction of insulin resistance. Thus, it demonstrates very early steps in the pathophysiology of type 2 diabetes, detectable in first-degree relatives who have normal glucose tolerance.

Finally, elevated fasting plasma glucagon levels were observed after dexamethasone, but the degree of suppression of 
glucagon did not differ during the clamps before and after dexamethasone or between the GLP-1 and GIP clamps. This finding suggest that fasting hyperglucagonaemia is a very early feature in the pathophysiology of type 2 diabetes, which is in accordance with earlier findings in insulin-resistant obese people with normal glucose tolerance [29].

In conclusion, a 5 day treatment with dexamethasone that induces a dysglycaemic state leads to early and possibly specific defects in the insulinotropic actions of incretin hormones. The findings suggest that the reduced ability of incretin hormones to stimulate insulin secretion, which is the main reason for the reduction in the incretin effect in type 2 diabetes, is already present in a very early state before type 2 diabetes develops.

Acknowledgements We acknowledge the excellent technical assistance of bioanalyst A. Sattari (Department of Endocrinology, Bispebjerg University Hospital, Copenhagen, Denmark), bioanalyst J. Nyman (Department of Endocrinology, Hvidovre University Hospital, Hvidovre, Denmark) and bioanalyst S. Pilgaard (The NNF Center for Basic Metabolic Research and Department of Biomedical Sciences, University of Copenhagen, Copenhagen, Denmark). Parts of this study were presented in abstract form at the annual meeting of the American Diabetes Association, Chicago, June 2013.

Funding This study was supported by a grant from the Novo Nordisk Foundation.

Duality of interest The authors declare that there is no duality of interest associated with this manuscript.

Contribution statement $\mathrm{ME}$ collected and analysed the data and drafted the manuscript. ST collected data. TK generated the concept. DHJ, JJH and SM generated data. All authors made significant contributions to the design of the study, or to the analysis and interpretation of presented data as well as to drafting the article or revising it critically and all gave their approval for the final version. TK is responsible for the integrity of the work as a whole.

\section{References}

1. Holst JJ (2007) The physiology of glucagon-like peptide 1 . Physiol Rev 87:1409-1439

2. Dube PE, Brubaker PL (2004) Nutrient, neural and endocrine control of glucagon-like peptide secretion. Horm Metab Res 36:755-760

3. Holst JJ, Deacon CF, Vilsboll T, Krarup T, Madsbad S (2008) Glucagon-like peptide-1, glucose homeostasis and diabetes. Trends Mol Med 14:161-168

4. Nauck M, Stockmann F, Ebert R, Creutzfeldt W (1986) Reduced incretin effect in type 2 (non-insulin-dependent) diabetes. Diabetologia 29:46-52

5. Perley MJ, Kipnis DM (1967) Plasma insulin responses to oral and intravenous glucose: studies in normal and diabetic subjects. J Clin Invest 46:1954-1962

6. Muscelli E, Mari A, Natali A et al (2006) Impact of incretin hormones on beta-cell function in subjects with normal or impaired glucose tolerance. Am J Physiol Endocrinol Metab 291:E1144E1150
7. Muscelli E, Mari A, Casolaro A et al (2008) Separate impact of obesity and glucose tolerance on the incretin effect in normal subjects and type 2 diabetic patients. Diabetes 57:1340-1348

8. Kjems LL, Holst JJ, Volund A, Madsbad S (2003) The influence of GLP-1 on glucose-stimulated insulin secretion: effects on \{beta\}-cell sensitivity in type 2 and nondiabetic subjects. Diabetes 52:380-386

9. Vilsboll T, Krarup T, Madsbad S, Holst JJ (2002) Defective amplification of the late phase insulin response to glucose by GIP in obese type II diabetic patients. Diabetologia 45:1111-1119

10. Jensen DH, Aaboe K, Henriksen JE et al (2012) Steroid-induced insulin resistance and impaired glucose tolerance are both associated with a progressive decline of incretin effect in first-degree relatives of patients with type 2 diabetes. Diabetologia 55:1406-1416

11. Hojberg PV, Vilsboll T, Rabol R et al (2009) Four weeks of nearnormalisation of blood glucose improves the insulin response to glucagon-like peptide-1 and glucose-dependent insulinotropic polypeptide in patients with type 2 diabetes. Diabetologia 52:199-207

12. Meier JJ, Nauck MA (2010) Is the diminished incretin effect in type 2 diabetes just an epi-phenomenon of impaired beta-cell function? Diabetes 59:1117-1125

13. Alberti K, Zimmet PZ (1998) Definition, diagnosis and classification of diabetes mellitus and its complications. Part 1: diagnosis and classification of diabetes mellitus - provisional report of a WHO consultation. Diabet Med 15:539-553

14. WHO (2006) Definition and diagnosis of diabetes mellitus and intermediate hyperglycemia: report of a WHO/IDF consultation. World Health Organization, Geneva

15. Nauck MA, Liess H, Siegel EG, Niedmann PD, Creutzfeldt W (1992) Critical evaluation of the 'heated-hand-technique' for obtaining 'arterialized' venous blood: incomplete arterialization and alterations in glucagon responses. Clin Physiol 12:537-552

16. Orskov C, Rabenhoj L, Wettergren A, Kofod H, Holst JJ (1994) Tissue and plasma concentrations of amidated and glycineextended glucagon-like peptide I in humans. Diabetes 43:535-539

17. Krarup T, Holst JJ (1984) The heterogeneity of gastric inhibitory polypeptide in porcine and human gastrointestinal mucosa evaluated with five different antisera. Regul Pept 9:35-46

18. Krarup T, Madsbad S, Moody AJ et al (1983) Diminished immunoreactive gastric inhibitory polypeptide response to a meal in newly diagnosed type I (insulin-dependent) diabetics. J Clin Endocrinol Metab 56:1306-1312

19. Orskov C, Jeppesen J, Madsbad S, Holst JJ (1991) Proglucagon products in plasma of noninsulin-dependent diabetics and nondiabetic controls in the fasting state and after oral glucose and intravenous arginine. J Clin Invest 87:415-423

20. Baldissera FG, Holst JJ (1984) Glucagon-related peptides in the human gastrointestinal mucosa. Diabetologia 26:223-228

21. Holst JJ, Pedersen JH, Baldissera F, Stadil F (1983) Circulating glucagon after total pancreatectomy in man. Diabetologia 25:396-399

22. Kjems LL, Christiansen E, Volund A, Bergman RN, Madsbad S (2000) Validation of methods for measurement of insulin secretion in humans in vivo. Diabetes 49:580-588

23. Matthews DR, Hosker JP, Rudenski AS, Naylor BA, Treacher DF, Turner RC (1985) Homeostasis model assessment: insulin resistance and beta-cell function from fasting plasma glucose and insulin concentrations in man. Diabetologia 28:412-419

24. Hansen KB, Vilsboll T, Bagger JI, Holst JJ, Knop FK (2011) Increased postprandial GIP and glucagon responses, but unaltered GLP-1 response after intervention with steroid hormone, relative physical inactivity, and high-calorie diet in healthy subjects. $\mathrm{J}$ Clin Endocrinol Metab 96:447-453

25. Tappy L, Randin D, Vollenweider P et al (1994) Mechanisms of dexamethasone-induced insulin resistance in healthy humans. J Clin Endocrinol Metab 79:1063-1069

26. McMahon M, Gerich J, Rizza R (1988) Effects of glucocorticoids on carbohydrate metabolism. Diabetes Metab Rev 4:17-30 
27. Coderre L, Srivastava AK, Chiasson JL (1992) Effect of hypercorticism on regulation of skeletal muscle glycogen metabolism by insulin. Am J Physiol 262:E427-E433

28. Henquin JC, Nenquin M, Stiernet P, Ahren B (2006) In vivo and in vitro glucose-induced biphasic insulin secretion in the mouse: pattern and role of cytoplasmic $\mathrm{Ca}^{2+}$ and amplification signals in beta-cells. Diabetes 55:441-451

29. Knop FK, Aaboe K, Vilsboll T et al (2012) Impaired incretin effect and fasting hyperglucagonaemia characterizing type 2 diabetic subjects are early signs of dysmetabolism in obesity. Diabetes Obes Metab 14:500 510

30. Meier JJ, Hucking K, Holst JJ, Deacon CF, Schmiegel WH, Nauck MA (2001) Reduced insulinotropic effect of gastric inhibitory polypeptide in first-degree relatives of patients with type 2 diabetes. Diabetes 50:2497-2504
31. Meier JJ, Gallwitz B, Askenas M et al (2005) Secretion of incretin hormones and the insulinotropic effect of gastric inhibitory polypeptide in women with a history of gestational diabetes. Diabetologia 48: $1872-1881$

32. Kahn SE, Horber FF, Prigeon RL, Haymond MW, Porte D Jr (1993) Effect of glucocorticoid and growth hormone treatment on proinsulin levels in humans. Diabetes 42:1082-1085

33. Fritsche A, Stefan N, Hardt E, Schützenauer S, Häring H, Stumvoll M (2000) A novel hyperglycaemic clamp for characterization of islet function in humans: assessment of three different secretagogues, maximal insulin response and reproducibility. Eur J Clin Investig 30:411-418

34. Nauck MA, Heimesaat MM, Orskov C, Holst JJ, Ebert R, Creutzfeldt W (1993) Preserved incretin activity of glucagon-like peptide 1 [7-36 amide] but not of synthetic human gastric inhibitory polypeptide in patients with type-2 diabetes mellitus. J Clin Invest 91:301-307 